Received: March 3, 1999

\title{
Tuberculoma of the Spermatic Cord
}

\author{
M.K. Al-Meshaan H.A.R. Afif \\ Department of Surgery, Urology Unit, Al-Sabah Hospital, Kuwait
}

\section{Key Words}

Genitourinary tuberculosis · Spermatic cord tuberculoma

\footnotetext{
Abstract

Objective and importance: Tuberculoma of the intrascrotal cord is rare. There were only 8 other cases reported in the English literature. Clinical presentation: A 40-year-old man presented with a painless mass in the left scrotal region. Preoperated frozen section showed it to be a tuberculous lesion. Intervention or technique: The mass was excised in toto and the final histopathology confirmed the frozen section and antituberculous drugs were administered. Conclusion: An awareness of this condition would prevent an orchidectomy on the patient for a benign lesion.
}

\section{Introduction}

Tuberculoma of the spermatic cord was reported in 115 cases in the Japanese literature. Intrascrotal tuberculoma is rare, and only 8 cases were reported in the English literature so far [1]. This condition is difficult to distinguish from malignant tumors in the scrotum.

Preoperative diagnosis is important to avoid performing an extensive surgery (orchidectomy) for a benign lesion. Unfortunately, 6/8 of these patients with intrascrotal tuberculoma were subjected to unnecessary orchidectomy [2, 3]. This is a report of another case of intrascrotal tuberculoma which was managed by limited excision of the mass after confirming the diagnosis by preoperative frozen section.

\section{Case Report}

A 40-year-old patient from Bangladesh presented to the Urological Outpatient Clinic with a 2-month history of a painless left scrotal mass. The patient gave no

\begin{tabular}{|c|c|c|}
\hline KARGER & $\begin{array}{l}\text { (c) } 1999 \text { S. Karger AG, Basel } \\
1011-7571 / 99 / 0083-0251 \$ 17.50 / 0\end{array}$ & $\begin{array}{l}\text { Dr. M.K. Al-Meshaan } \\
\text { PO Box } 3360 \\
\text { Safat } 13034 \text { (Kuwait) }\end{array}$ \\
\hline arger.ch & $\begin{array}{l}\text { Accessible online at: } \\
\text { http://BioMedNet.com/karger }\end{array}$ & Tel. +965 4843222, Fax +9654836201 \\
\hline
\end{tabular}


Fig. 1. Macroscopic appearance of tuberculoma of the spermatic cord. Excised completely.

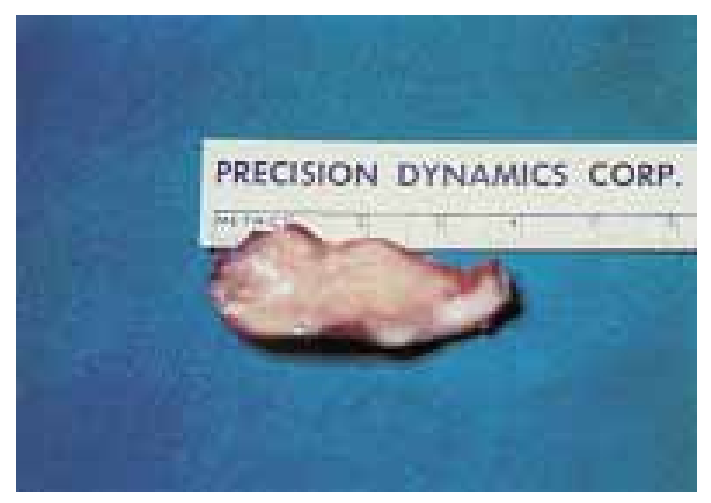

Fig. 2. Microscopic appearance of the tuberculoma. HE. $\times 65$. $\longrightarrow$ = Caseation

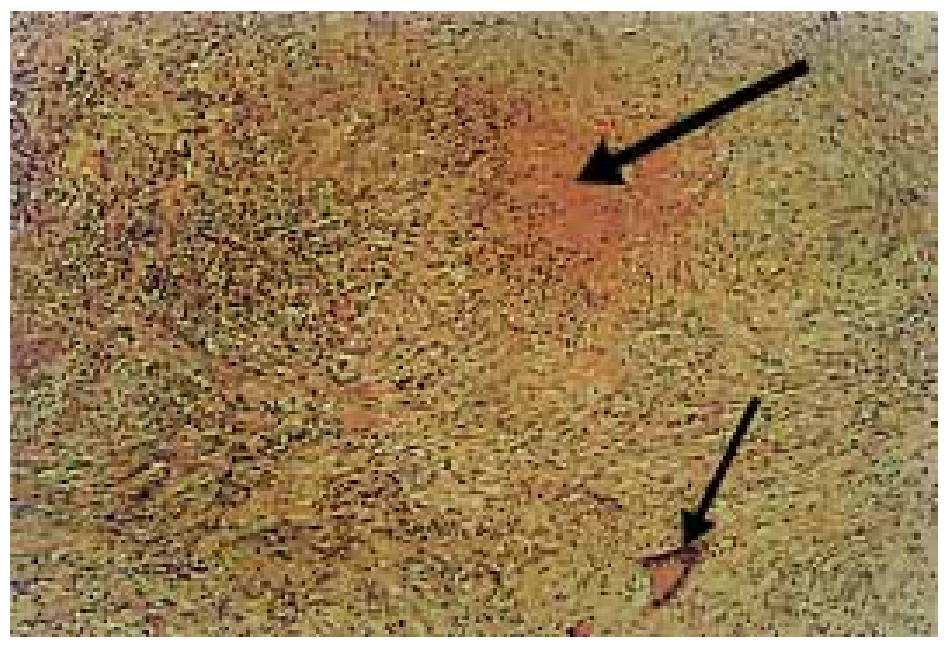

Fig. 3. Evidence of vasculitis granuloma with giant cell (arrow). HE. $\times 65$.

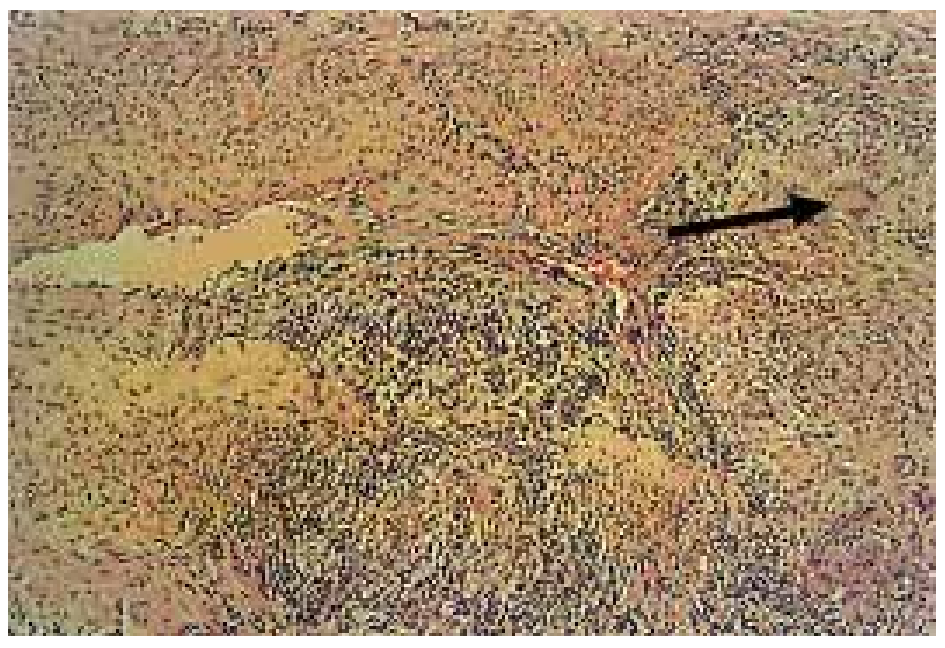


history of trauma, loss of weight or any serious illness. There was no history of urinary trouble.

On examination, there was a well-defined, firm nontender mass in the left scrotal compartment, which was neither attached to the testis nor to the epididymis. Clinical and ultrasound examinations revealed normal testes, epididymis, inguinal nodes and prostate. The mass was $4 \times 1.5 \times 1 \mathrm{~cm}$. A preoperative chest X-ray was reported to be normal. Routine tests, blood and urine were all within normal values except for an elevated ESR at $52 \mathrm{~mm} / \mathrm{h}$ (normal value $0-8 \mathrm{~mm} / \mathrm{h}$ ).

It was decided to explore the mass. The lesion was attached to the spermatic cord but had no skin involvement. All precautions were taken as if dealing with malignancy of the cord, i.e. soft clamp on the cord to avoid tumor dissemination; the mass was dissected and excised, and no anastomosis of the cord was required. Frozen section of the mass showed granuloma formation with high possibility of tuberculosis (fig. 1). It was decided therefore that simple excision is sufficient and the wound was closed. The final pathologic report showed multiple epitheloid granulomas, some of which displayed central caseation. In addition, there was a diffuse mononuclear inflammatory cell infiltrate rich in plasma cells and lymphocytes (fig. 2). Granulomatous vasculitis as well as areas of hyaline fibrosis were present (fig. 3). Special stains for fungus and acid-fast bacilli were negative.

Postoperatively, sputum, early morning urine and semen were negative for acid-fast bacilli. A PPD skin test resulted in a 14-mm weal. Because of the vasculitis serological tests for cytoplasmic antineutrophil antibodies, antistreptolysin $(\mathrm{O})$ titer and $\mathrm{Rh}$ factor were performed to exclude autoimmune disorders. These tests were normal. Accordingly, the case was diagnosed as tuberculoma of the cord and the patient was started on a 9-month course of antituberculous treatment consisting of rifampicin, isoniazid and pyrazinamide.

The patient made an uneventful recovery and was discharged from the hospital. He was regularly followed up in the Urology Outpatient Clinic. He remains healthy with no complaints. At 1 year after treatment his ESR is down to normal $8 \mathrm{~mm} / \mathrm{h}$ and PPD is now 7-mm weal (no induration).

\section{Discussion}

Tuberculosis $(\mathrm{TB})$ is recurring everywhere especially among the underprivileged and AIDS patients [4]. TB usually reaches the low- er genitourinary tract by hematogenous spread or by descent from an infected kidney. It occurs in $<1 \%$ of patients with pulmonary infection [5] and is a disease of the sexually active male. Constitutional symptoms such as fever, night sweats and loss of weight are not usually seen in patients with genitourinary TB. TB of the spermatic cord is not uncommon $[1,6,7]$. It most commonly presents in the inguinal region. Spermatic cord TB has been reported in about 115 cases in the Japanese literature [1]. However, intrascrotal tuberculoma seems to be rare. There were only 8 cases reported in the English literature [1]. Other conditions can cause a mass in the cord, i.e. lymphoma, rhabdomyosarcoma, adenomatoid cyst, and adrenal rest. The importance of these lesions is that they can mimic malignancy and it has been advised that such swellings should be managed as suspect testicular tumors [6]. Unfortunately, 6 out of the 8 reported intrascrotal tuberculoma patients had mistakenly undergone orchidectomy for suspected malignancy. It is prudent therefore that every effort should be made for a pre- or perioperative diagnosis to avoid such an unforgivable mistake.

Up to $70 \%$ of the patients with genitourinary TB have dormant or active pulmonary disease $[8,9]$. It is therefore incumbent on the treating doctor to rule out this possibility. Patients with or without extragenital infection should receive full antituberculous therapy for at least 1 month [7].

In conclusion this report emphasizes a few points in managing a painless intrascrotal mass: (a) Preoperative frozen section is helpful in excluding malignancy and avoiding unnecessary orchidectomy. (b) Limited resection of the mass with preservation of the testis and epididymis seems to be sufficient in the management of such cases. (c) Once the diagnosis is confirmed, anti-TB therapy should be continued for 9-12 months. (d) High ESR in 
an otherwise healthy patient should raise the suspicion. In addition, ESR can be monitored in the follow-up of these patients. A drop in the ESR value is probably an indication of response to therapy.

\section{References}

1 Yamasaki S, Sugita O, Tanimura M Morioka M: Tuberculoma arising in the inguinal portion of the spermatic cord. Int J Urol 1996;3:514-517.

2 Tajika E, Nakamura T, Iwasa Y, Kitagawa M: Tuberculosis of the spermatic cord (in Japanese). J Clin Urol 1984;38:77-79.

3 Martinicllo R, Manzi A, Maranelli C: Pseudotumoral tuberculosis of the spermatic cord. Minerva Urol Nefrol 1984;36:133-134.

\section{Acknowledgments}

The authors acknowledge the assistance of Dr. Sami Asfar and Prof. Hussein Dashti, Department of Surgery, Faculty of Medicine, Kuwait University, and Dr. K.C. Kacthy, Head of the Pathology Department, Sabah Hospital.
4 Center for Disease Control and Prevention: Tuberculosis morbidity: United States, 1994. MMWR Morb Mortal Wkly Rep 1995;44:387389.

5 Gorse GJ, Belshe RB: Male genital tuberculosis: A review of the literature with instructive case report. Rev Infect Dis 1985; 7:511-524.

6 Jacobs SC: Spermatic cord tuberculomas. Urology 1977;9:566-567.
7 Gokalp A, Gultekin EY: Oztamar S: Genito-urinary tuberculosis: A review of 83 cases. Br J Clin Prac 1990;44:599-600.

8 Heaton ND, Hogan B, Thompson P, Yates-Bell AJ: Tuberculous epididymo-orchitis: Clinical and ultrasound observation. Br J Urol 1989;64: 305-309.

9 Henegan AM, Livingstone R: Genital tuberculosis in an adolescent male. Arch Pediatr Adolesc Med 1997;11:526-527. 